\title{
G

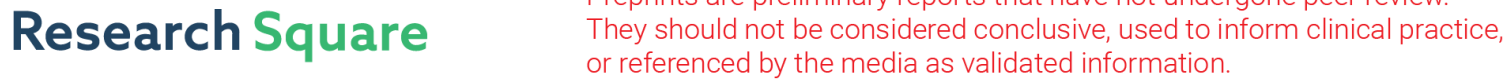 \\ 60-day survival of critically ill COVID-19 first comers
}

\section{Corinna N. Lang ( $\nabla$ corinna.nadine.lang@uniklinik-freiburg.de )}

Heart Center Freiburg University, Department of Cardiology and Angiology I, Faculty of Medicine, University of Freiburg, Freiburg, Germany

\section{Zotzmann}

Heart Center Freiburg University, Department of Cardiology and Angiology I, Faculty of Medicine, University of Freiburg, Freiburg, Germany

\section{B. Schmid}

Department of Emergency Medicine, University Hospital of Freiburg, Faculty of Medicine, University of Freiburg, Freiburg, Germany

\section{Berchtold-Herz}

Heart Center Freiburg University, Department of Cardiovascular Surgery, Faculty of Medicine, University of Freiburg, Freiburg, Germany

\section{S. Utzolino}

Department of General and Visceral Surgery, Medical Center, University of Freiburg, Freiburg, Germany

\section{P.M. Biever}

Heart Center Freiburg University, Department of Cardiology and Angiology I, Faculty of Medicine, University of Freiburg, Freiburg, Germany

\section{T. Pottgießer}

Heart Center Freiburg University, Department of Cardiology and Angiology I, Faculty of Medicine, University of Freiburg, Freiburg, Germany

\section{Duerschmied}

Heart Center Freiburg University, Department of Cardiology and Angiology I, Faculty of Medicine, University of Freiburg, Freiburg, Germany

\section{Bode}

Heart Center Freiburg University, Department of Cardiology and Angiology I, Faculty of Medicine, University of Freiburg, Freiburg, Germany

\section{T. Wengenmayer}

Heart Center Freiburg University, Department of Cardiology and Angiology I, Faculty of Medicine, University of Freiburg, Freiburg, Germany

\section{D.L. Staudacher}

Heart Center Freiburg University, Department of Cardiology and Angiology I, Faculty of Medicine, University of Freiburg, Freiburg, Germany

\section{Research Article}


Keywords: COVID-19, ARDS, 60-day survival, ICU resources, outcome

Posted Date: August 2nd, 2020

DOI: https://doi.org/10.21203/rs.3.rs-50651/v1

License: (c) (1) This work is licensed under a Creative Commons Attribution 4.0 International License. Read Full License 


\section{Abstract}

Background: Germany reported sufficient intensive care unit (ICU) resources throughout the first wave of coronavirus disease 2019 (COVID-19). The treatment of critically ill COVID-19 patients without rationing may improve the outcome. We therefore analyzed resources allocated to critically ill COVID-19 patients and their outcomes.

Methods: Retrospectively, we enrolled SARS-CoV2 PCR positive patients with respiratory failure from $03 / 08 / 2020$ to $04 / 08 / 2020$ and followed until $05 / 28 / 2020$ in the university hospital of Freiburg, Germany.

Results: Thirty-four COVID-19 patients were admitted to the ICU in the defined interval with medium age of $67 \pm 13(31-86)$ years. $6 / 34(17.6 \%)$ were female. All patients suffered from moderate or severe acute respiratory distress syndrome (ARDS), $91.2 \%$ of the patients were intubated and $23.5 \%$ required extracorporeal membrane oxygenation (ECMO). Proning was performed in $67.6 \%$, renal replacement therapy (RRT) was required in $35.3 \%$. 96\% required more than 20 nursing hours per day. Mean ICU stay was $21 \pm 19$ (1-81) days. 60-day survival of critically ill COVID-19 patients was $50.0 \%$ (17/34). Causes of death were multi-organ failure (52.9\%), refractory ARDS (17.6\%) and intracerebral hemorrhage (17.6\%).

Conclusions: Treatment of critically ill COVID-19 patients is protracted and resource intense. In a context without resources shortage, $50 \%$ of critically ill COVID-19 survived up to 60 days.

\section{Background}

Severe acute respiratory coronavirus 2 (SARS-CoV-2) pandemic encountered southwestern Germany in March 2020, causing relevant case numbers of the virus-related pneumonia (COVID-19). Clinical courses of critically ill patients with COVID-19 were characterized in international cohorts with mortality rates between 50 and $88 \%$ (including ongoing treatment cohorts).(1-3) The overall case fatality rates vary internationally (1-12\%). Recently, reported case fatality rates in Germany remain lower than in neighboring countries. There are no convincing explanations for this phenomenon, whereas only limited data is available for critically ill patients in Europe and their outcomes. $(3,4)$

Patients with severe pulmonary failure and adult respiratory distress syndrome (ARDS) are reported to require multiple organ replacement therapies, some of which have to be applied at the same time. As recently reported, severity of COVID-19 cases immensely increases the strain on staff and resources.(1)

This retrospective study analyzes the first cohort of patients on three intensive care units at a third-level treatment center in Freiburg, Germany. During the observation period the center never faced a shortage of human or technical resources for the treatment of those patients with ARDS caused by COVID-19. The 
present study focuses on the necessary resources for the treatment, the complications, and hospital survival.

\section{Methods}

We enrolled critically ill patients in case of PCR-confirmed SARS-CoV-2 infection and intensive care unit (ICU) admission due to pulmonary failure caused by COVID-19 from 03/08/2020 (date of ICU admission of our first case) to $04 / 08 / 2020$.

\section{ARDS treatment}

The ARDS treatment followed current guidelines and house-intern standard operating procedures for lung-protective ventilation, prone positioning and supportive therapies.(5) In case of hypoxia or hypercapnia in patients with lung-protective ventilation, ECMO was evaluated by an interdisciplinary team of at least one ECMO specialist, a registered nurses and a perfusionist following local standards.

\section{$\underline{\text { Inclusion criteria }}$}

According to the local pandemic plan, COVID-19 patients were treated at different intensive care units (medical, and surgical). Patients were admitted to out hospital from the emergency room (ER), regular hospital wards, or from first and secondary treatment centers. Our center serves as a reference and referral center for ARDS and ECMO offering a 24/7 ECMO retrieval service. All patients with proven SARSCoV2 infection and severe respiratory failure requiring ICU therapy were included in the present study. The PCR tests were carried out from nasopharyngeal swabs or tracheal secretion. Patients with high clinical probability of COVID-19 but negative virology testing were excluded.

\section{Endpoint definition:}

ARDS was classified according to the Berlin classification (6), Kidney injury according to the RIFLE definition. All patients dismissed home were considered 60-day survivors in regards to this study. The cause of death was determined by clinical judgment of at least two intensivists part of this research project.

\section{Data management}

The data collection was carried out till 05/28/2020. We extracted patient related data from our hospital data systems and documentation from transferring hospitals. The local ethics committee approved the study protocol (Ethik-Kommission der Albert-Ludwigs-Universität Freiburg file number 234/20). Hospital survival was defined as discharge from the ICU on a step-down unit / regular ward or hospital discharge. Non-survivors and ICU-survivors were compared with chi-square test and univariate ANOVA. Patients with ongoing therapies were excluded from testing differences. We performed analyses with SPSS, version 26 (IBM, NYC, USA) and Prism, version 8 (GraphPad, San Diego, USA) and a p-value of $<0.05$ was considered statistically significant 


\section{Results}

\section{Baseline characteristics and comorbidities}

During the observation period, 34 COVID-19 patients with pulmonary failure were admitted and treated on the ICU. Medium age was $67 \pm 13$ years, $6(17.6 \%)$ were female.

The medical history of the patients comprised overweight (76.5\%), hypertension (52.9\%), diabetes $(25.3 \%)$ and cardiac diseases $(23.5 \%$ coronary artery disease, $17.6 \%$ valve operation or chronic heart failure heart). The number of patients with chronic respiratory precondition was low (Table 1).

Simplified Acute Physiology Score (SAPS) II score was significantly higher in non-survivors compared to survivors ( $50 \pm 7$ vs. $42 \pm 14 ; p=0.037$ ). No other significant differences in comorbidities were found.

Assessment of symptoms, vitals on admission, virologic findings, microbiological findings, the laboratory measures and imaging are presented in the supplemental material (Table S1).

\section{$\underline{\mathrm{ICU} \text { resources and management }}$}

Length of ICU treatment in non-survivors was $17 \pm 7$ (2-72) days, patients discharged from ICU were treated $25 \pm 22$ (1-81) days (Table 2). The dates of arrival, cumulative therapies and outcomes of individual patients are displayed in figure 1 .

Half of our patients suffered from moderate, half of severe ARDS. Intubation was performed in $91.2 \%$ of the cases, prior to the intubation in 10 patients (29.4\%) nasal high flow (NHF) and / or non-invasive ventilation (NIV) was applied.

Three patients (8.8\%) were exclusively managed with NHF / NIV. On average, patients were on invasive mechanical ventilation (IMV) for 19 \pm 21 (0-79) days. Positive end-expiratory pressure (PEEP) levels were high during the three first treatment days on average $12.5 \pm 3$ (7-18) mbar. Spontaneous breathing on the ventilator was performed in $73.5 \%$ in the first 24 hours. Weaning from the respirator was successfully completed in 12 cases before ICU discharge, 5 patients went to a weaning unit.

Veno-venous extracorporeal membrane oxygenation (ECMO) therapy was installed in 8/34 (23.5\%) patients for $20 \pm 23$ (2-75) days. Three patients were weaned from ECMO therapy. 2 patients died of refractory ARDS and 2 because of intracerebral hemorrhage during ECMO, one patient died with abdominal sepsis and bleeding during ECMO therapy.

Proning was performed in $67.6 \%$. If proning was not indicated, alternative strategies were incomplete prone positioning $\left(135^{\circ}\right)$, pilot's seat positioning or the use of a rotational bed. Thus, $88.2 \%$ of our patients underwent daily therapeutic positioning maneuvers.

Acute kidney injury was noticed in $85.3 \%$ of the patients, renal replacement therapy (RRT) was required in $35.3 \%$ of all cases. Due to vasoplegic or cardiogenic shock, non-survivors significantly more often 
required vasopressor therapy $(17 / 17$ vs. $11 / 17 ; p=0.007)$ and transfusions $(12 / 17$ vs. $5 / 17 ; p=0.016)$.

The initial antiviral treatment followed house-intern expert consensus and was a combination of hydrochloroquine and lopinavir/ritonavir (70.6\%) and later on a hydrochloroquine only treatment (23.5\%). Five patients received tocilizumab (14.7\%). Additional information is presented in the supplements (Table S2).

Resource intense multi-organ replacement ICU treatment was measured in nursing hours using Inpuls $®$ categories in 25 patients. A time investment of $>20$ hours per day was necessary in $96.0 \%$ of our patients and required a 1:1 nurse-patient ratio. Additional information is presented in the supplements. The cumulative therapies are displayed in figure 2 .

\section{Outcomes and complications}

At the end of the follow up, exactly half of our patients were dead, the other half was discharged from ICU, including 5 transferals to weaning units (4 in-house transferals). More than half of the survivors were able to be discharged home (58.8\%), 2 went on a rehabilitation therapy without oxygen supply. On average the survival since admission was $60 \pm 8$ days (51-81 days).

The clinical course was complicated by pneumothorax or pneumomediastinum in 6 (17.6\%) cases. Furthermore, 5 (14.7\%) patients exhibited non-fatal pulmonary embolism / thrombosis in segmental and sub-segmental lung arteries. Superinfections during treatment in 18 (52.9\%) cases were dominated by Serratia marcescens (33.3\%). Aspergillus fumigatus superinfection was detected in 2 (11.1\%) patients (Table 3). Intracerebral hemorrhage was significantly more often recorded in non-survivors $(p=0.015)$.

Nine $(52.9 \%)$ patients died because of untreatable multi-organ failure as the main cause of death in the cohort. Three (21.4\%) patients died because of refractory ARDS. Notably, 3/17 (17.6\%) patients died of fatal intracerebral hemorrhage. Because of SARS-CoV-2 PCR positivity organ donation was impossible in these patients. Two (11.8\%) patients did not continue therapy because of "do not resuscitate" (DNR) orders and received palliative treatment. No medical autopsies were carried out in this cohort (Table 3 ).

\section{Discussion}

We present a 60-day follow-up of our first critically ill COVID-19 patients due to pulmonary failure in southwestern Germany. The age and common comorbidities were similar to international cohorts. $(1-3,7)$ In our cohort, 60 -day survival was $50.0 \%$. Importantly, the majority of our survivors were able to return into their former lives.

This is similar to the case-fatality rate of $49.0 \%$ reported for "critical cases" in a large Wuhan registry (8) and much lower than suggested by early reports in the COVID-19 pandemic for patients with severe pulmonary failure. $(2,3)$ Importantly, we present data with a long follow-up. In other registries a very small number of patients actually could return to normal life. $(2,3)$ Therefore, we can report a sounder estimate of prognosis of COVID-19 patients. 
As Germany did not experience a shortage of ICU resources, it is not surprising that in our cohort, ICU therapy lasted longer than reported in other registries.(1,9) Also, more resources were allocated to patients in this registry including multiple organ replacement therapies - ECMO therapies (1) and renal replacement therapy was required more often than reported in other cohorts from Wuhan or New York.(13) Another German registry similar rates of ECMO and renal replacement therapy.(3) We are the first to report an estimate on the enormous amounts of nursing hours required for treating these patients.

As for cause of death, only $17.6 \%$ died from refractory respiratory failure. Data of 92 COVID-19 associated deaths states ARDS as the main complication followed by myocardial injury, liver and kidney injury and multiple organ failure.(10) In pandemic conditions, resource shortages might necessitate rapid decisions regarding futility compared to normal conditions. Survival rate in the present study is lower than described for a general ARDS population (60-day survival $68 \%(11)$ ). When considering, that ARDS mortality is lower in tertiary hospitals than in hospitals of first and second treatment level (12), the high mortality found in this registry might suggest a significant case-fatality rate of COIVD-19 patients requiring ICU therapy. According to the SAPS II score, our cohort had a relatively high predicted risk of death (over $40 \%$ ), which is higher than in cohorts characterized beforehand. Also, many patients treated on our ICU were transferred for severe pulmonary failure and ECMO evaluation. Therefore, considering the small patient numbers and the lack of a control group, we cannot compare mortality of COVID-19 patents with ARDS to other ARDS patients.

As stated by Klok et al. the incidence of thrombotic complications is up to $31 \%$ in COVID-19 patients on the ICU.(4) The notable rate of $14.7 \%$ non-fatal pulmonary artery thrombosis is in line with their findings. Further studies concentrated on autopsies and confirmed a high rate of thrombembolic events.(13) At the moment the underlying mechanism for the coagulopathy leading to pulmonary artery thrombosis and cerebral bleeding, which were leading causes of the complications in this cohort, is unknown.

Nevertheless, the coagulopathic state in COVID-19 does not only seem to lead to thrombotic events as documented, but also to a relevant rate of bleedings. In the cohort five intracerebral hemorrhages occurred, three being fatal.

\section{Limitations:}

First, the case number is limited and the data has to be verified by larger cohorts and longer follow-up intervals. Second, the cohort is a selected one as the university hospital of Freiburg is a tertiary center. The center has a large number of patient allocations from primary or secondary treatment centers because of evaluation of ECMO therapy or limited resources in the other centers.

\section{Conclusions}

Caring for critically ill COVID-19 patients requires an immense amount of organ replacement therapies, nursing hours and ICU days. The 60 -days survival is $50 \%$ in a German tertiary treatment center despite full resources. High mortality in COVID-19 might be disease-specific rather than caused by resource shortage. 


\section{List Of Abbreviations}

ARDS, severe acute respiratory distress syndrome

BMI, body mass index

COVID-19, coronavirus disease 2019

DNR order, do not resuscitate order

ER, emergency room

ECMO, extracorporeal membrane oxygenation

ICU, intensive care unit

Inpuls ${ }^{\circledR}$, Intensivpflege- und Leistungserfassungssystem (Inpuls ${ }^{\circledR}$, Heidelberg, Germany)

IMV, invasive mechanical ventilation

NHF, nasal high flow

NIV, non-invasive ventilation

NYC, New York City

P insp, inspiratory pressure

P peak, measured peak pressure

RRT, renal replacement therapy

SAPS II score, simplified acute physiology score14

SARS-CoV-2, severe acute respiratory coronavirus 2

PEEP, positive end-expiratory pressure

TISS Score, therapeutic intervention scoring system 15

\section{Declarations}

Ethics approval and consent to participate: The local ethics committee approved the study protocol; verbal or written consent was deemed unnecessary (Ethik-Kommission der Albert-Ludwigs-Universität Freiburg im Breisgau 234/20). 
Availability of data and materials: The datasets analyzed during the current study are available from the corresponding author on reasonable request.

Competing interests: The authors declare that they have no competing interests or conflict of interests.

Funding: This research did not receive any specific grant from funding agencies in the public, commercial, or non-for-profit sectors. The article processing charge was funded by the BadenWuerttemberg Ministry of Science, Research and Art and University of Freiburg in the funding program Open Access Publishing.

Authors' contributions: CNL concepted and designed the study, performed data acquisition, interpretation of the data, drafted and revised the manuscript. VZ concepted and performed data acquisition and revised the manuscript. BS was a major contributor in analysis, interpretation of the data, writing the manuscript. BH contributed in interpretation of the data and revising the manuscript. SU contributed in interpretation of the data and revising the manuscript. PB contributed in interpretation of the data and revising the manuscript. TB contributed in interpretation of the data and revising the manuscript. DD contributed in interpretation of the data and revising the manuscript. CMB contributed in interpretation of the data and revising the manuscript. TW contributed in interpretation of the data and revising the manuscript. DLS concepted and designed the study, created the artwork, contributed in interpretation of the data and revising the manuscript. All authors read and approved the final manuscript.

Acknowledgements: not applicable.

\section{References}

1. Yang $X, Y u Y, X u$ J, Shu H, Xia J, Liu H, u. a. Clinical course and outcomes of critically ill patients with SARS-CoV-2 pneumonia in Wuhan, China: a single-centered, retrospective, observational study. Lancet Respir Med. 2020;8(5):475-81.

2. Richardson S, Hirsch JS, Narasimhan M, Crawford JM, McGinn T, Davidson KW, u. a. Presenting Characteristics, Comorbidities, and Outcomes Among 5700 Patients Hospitalized With COVID-19 in the New York City Area. JAMA. 22. April 2020;

3. Dreher M, Kersten A, Bickenbach J, Balfanz P, Hartmann B, Cornelissen C, u. a. The Characteristics of 50 Hospitalized COVID-19 Patients With and Without ARDS. Dtsch Ärztebl Int. März 2020;117(10):271-8.

4. Klok FA, Kruip MJHA, van der Meer NJM, Arbous MS, Gommers D, Kant KM, u. a. Confirmation of the high cumulative incidence of thrombotic complications in critically ill ICU patients with COVID-19: An updated analysis. Thromb Res. 30. April 2020;

5. Alhazzani W, Møller MH, Arabi YM, Loeb M, Gong MN, Fan E, u. a. Surviving Sepsis Campaign: guidelines on the management of critically ill adults with Coronavirus Disease 2019 (COVID-19). Intensive Care Med. 2020;46(5):854-87. 
6. ARDS Definition Task Force, Ranieri VM, Rubenfeld GD, Thompson BT, Ferguson ND, Caldwell E, u. a. Acute respiratory distress syndrome: the Berlin Definition. JAMA. 20. Juni 2012;307(23):2526-33.

7. Arentz M, Yim E, Klaff L, Lokhandwala S, Riedo FX, Chong M, U. a. Characteristics and Outcomes of 21 Critically III Patients With COVID-19 in Washington State. JAMA. 28. April 2020;323(16):1612-4.

8. Wu Z, McGoogan JM. Characteristics of and Important Lessons From the Coronavirus Disease 2019 (COVID-19) Outbreak in China: Summary of a Report of 72314 Cases From the Chinese Center for Disease Control and Prevention. JAMA. 7. April 2020;323(13):1239-42.

9. Bhatraju PK, Ghassemieh BJ, Nichols M, Kim R, Jerome KR, Nalla AK, u. a. Covid-19 in Critically III Patients in the Seattle Region - Case Series. N Engl J Med [Internet]. 30. März 2020 [zitiert 29. Mai 2020]; Verfügbar unter: https://www.ncbi.nlm.nih.gov/pmc/articles/PMC7143164/

10. Yang F, Shi S, Zhu J, Shi J, Dai K, Chen X. Analysis of 92 deceased patients with COVID-19. J Med Virol. 15. April 2020;

11. Máca J, Jor O, Holub M, Sklienka P, Burša F, Burda M, u. a. Past and Present ARDS Mortality Rates: A Systematic Review. Respir Care. Januar 2017;62(1):113-22.

12. Raymondos K, Dirks T, Quintel M, Molitoris U, Ahrens J, Dieck T, u. a. Outcome of acute respiratory distress syndrome in university and non-university hospitals in Germany. Crit Care [Internet]. 30. Mai 2017 [zitiert 29. Mai 2020];21. Verfügbar unter: https://www.ncbi.nlm.nih.gov/pmc/articles/PMC5448143/

13. Wichmann D, Sperhake J-P, Lütgehetmann M, Steurer S, Edler C, Heinemann A, u. a. Autopsy Findings and Venous Thromboembolism in Patients With COVID-19: A Prospective Cohort Study. Ann Intern Med. 6. Mai 2020;

14. Le Gall JR, Lemeshow S, Saulnier F. A new Simplified Acute Physiology Score (SAPS II) based on a European/North American multicenter study. JAMA. 22. Dezember 1993;270(24):2957-63.

15. Cullen DJ, Civetta JM, Briggs BA, Ferrara LC. Therapeutic intervention scoring system: a method for quantitative comparison of patient care. Crit Care Med. April 1974;2(2):57-60.

\section{Tables}

Table 1: baseline characteristics ${ }^{\mathrm{a}}$ 


\begin{tabular}{|c|c|c|c|}
\hline & $\begin{array}{l}\text { non-survivors } \\
\qquad(\mathrm{n}=17)\end{array}$ & $\begin{array}{l}\text { survivors } \\
\qquad(\mathrm{n}=17)\end{array}$ & $\begin{array}{l}\text { all patients } \\
\qquad(\mathrm{n}=34)\end{array}$ \\
\hline number of patients & $17(50 \%)$ & $17(50 \%)$ & 34 \\
\hline age, years & $70 \pm 10(49-86)$ & $64 \pm 14(31-84)$ & $67 \pm 13(31-86)$ \\
\hline \multicolumn{4}{|l|}{ agge range, years } \\
\hline $30-49$ & $1(5.8 \%)$ & $2(11.8 \%)$ & $3(8.8 \%)$ \\
\hline $50-59$ & $2(11.8 \%)$ & $4(23.5 \%)$ & $6(17.6 \%)$ \\
\hline $60-69$ & $5(29.4 \%)$ & $4(23.5 \%)$ & $9(26.5 \%)$ \\
\hline $70-79$ & $6(35.3 \%)$ & $5(29.4 \%)$ & $11(32.4 \%)$ \\
\hline$\geq 80$ & $3(17.6 \%)$ & $2(11.8 \%)$ & $5(14.7 \%)$ \\
\hline \multicolumn{4}{|l|}{$\underline{\operatorname{sex}}$} \\
\hline female & $4(23.5 \%)$ & $2(11.8 \%)$ & $6(17.6 \%)$ \\
\hline DNR order & $4(23.5 \%)$ & $1(5.9 \%)$ & $5(14.7 \%)$ \\
\hline \multicolumn{4}{|l|}{$\underline{\text { location of admisson }}$} \\
\hline home/ER & $4(23.5 \%)$ & $1(5.9 \%)$ & $5(14.7 \%)$ \\
\hline internal hospital ward & $6(35.3 \%)$ & $9(52.9 \%)$ & $15(44.1 \%)$ \\
\hline hospital transfer & $7(41.2 \%)$ & $7(41.2 \%)$ & $14(41.2 \%)$ \\
\hline \multicolumn{4}{|l|}{ severity scores } \\
\hline SAPS II score & $50 \pm 7(42-70)$ & $42 \pm 14(15-69)$ & $46 \pm 12(15-70)$ \\
\hline TISS score & $16 \pm 5(10-28)$ & $8 \pm 23(0-31)$ & $14.8 \pm 7(0-31)$ \\
\hline Inpuls ${ }^{\circledR}$ & $5.5 \pm 0.5(5-6)$ & $5.2 \pm 0.8(3-6)$ & $5.3 \pm 0.7(3-6)$ \\
\hline \multicolumn{4}{|l|}{$\underline{\text { ARDS }}$} \\
\hline mild & 0 & 0 & 0 \\
\hline moderate & $7(41.2 \%)$ & $9(52.9 \%)$ & $17(50 \%)$ \\
\hline severe & $10(58.8 \%)$ & $7(41.2 \%)$ & $17(50 \%)$ \\
\hline \multicolumn{4}{|l|}{$\underline{\text { comorbidites }}$} \\
\hline BMI $(\mathrm{kg} / \mathrm{m} \rrbracket)$ & $29 \pm 5.5(18-39)$ & $28 \pm 3.7(23-35)$ & $28 \pm 4.6(18-39)$ \\
\hline$\geq 26 \mathrm{~kg} / \mathrm{m}$ & $13(76.5 \%)$ & $13(76.5 \%)$ & $26(76.5 \%)$ \\
\hline$\geq 30 \mathrm{~kg} / \mathrm{m}$ & $6(35.3 \%)$ & $5(29.4 \%)$ & $11(32.4 \%)$ \\
\hline
\end{tabular}

Page 11/17 


\begin{tabular}{|l|r|r|r|}
\hline hypertension & $9(52.9 \%)$ & $9(52.9 \%)$ & $18(52.9 \%)$ \\
\hline diabetes & $4(23.5 \%)$ & $8(47.1 \%)$ & $12(35.3 \%)$ \\
\hline HbA1c $\geq 6.5 \%$ & $2(11.8 \%)$ & $8(47.1 \%)$ & $10(29.4 \%)$ \\
\hline coronary artery disease & $5(29.4 \%)$ & $3(17.6 \%)$ & $8(23.5 \%)$ \\
\hline other cardiac disease ${ }^{b}$ & $5(29.4 \%)$ & $1(5.9 \%)$ & $6(17.6 \%)$ \\
\hline chronic respiratory disease & $3(17.6 \%)$ & $2(11.8 \%)$ & $5(14.7 \%)$ \\
\hline tobacco smoking & $6(35.3 \%)$ & $4(23.5 \%)$ & $10(29.4 \%)$ \\
\hline chronic kidney failure & $6(35.3 \%)$ & $2(11.8 \%)$ & $8(23.5 \%)$ \\
\hline cancer & $4(23.5 \%)$ & $4(23.5 \%)$ & $8(23.5 \%)$ \\
\hline immunosuppression & $1(5.9 \%)$ & $3(17.6 \%)$ & $4(11.8 \%)$ \\
\hline frailtyc & $6(35.3 \%)$ & $1(5.9 \%)$ & $7(20.6 \%)$ \\
\hline
\end{tabular}

Abbreviations: ICU, intensive care unit; BMI, body mass index (calculated in kilograms divided by height in meters squared); ER, emergency room; SAPS II score, Simplified Acute Physiology Score(14); TISS Score, Therapeutic Intervention Scoring System(15); Inpuls ${ }^{\circledR}$, Intensivpflege- und Leistungserfassungssystem, intensive care nursing and activity recording system (Inpuls ${ }^{\circledR}$, Heidelberg, Germany); ARDS = acute respiratory distress syndrome in accordance with the Berlin classification.(6)

If values of non-survivors and survivors were significantly different $(\mathrm{p}<0.05)$, we displayed them bold: SAPS II score $\mathrm{p}=0.037$.

a Baseline characteristics are displayed for all patients, non-survivors and survivors. Data are n (\%) or mean with standard deviation and range.

b Other cardiac condition = valve operation or chronic heart failure.

${ }^{\mathrm{c}}$ Frailty was clinically judged.

Table 2: ICU resources and therapy ${ }^{\mathrm{a}}$ 


\begin{tabular}{|c|c|c|c|}
\hline & $\begin{array}{l}\text { non-survivors } \\
\qquad(\mathrm{n}=17)\end{array}$ & $\begin{array}{l}\text { survivors } \\
\qquad(\mathrm{n}=17)\end{array}$ & $\begin{array}{l}\text { all patients } \\
\qquad(\mathrm{n}=34)\end{array}$ \\
\hline length of ICU stay & $17 \pm 17(2-72)$ & $25 \pm 22(1-81)$ & $21 \pm 19(1-81)$ \\
\hline \multicolumn{4}{|l|}{ ventilation } \\
\hline $\mathrm{NIV}+/-\mathrm{IMV}$ & $5(29.4 \%)$ & $8(47.1 \%)$ & $13(38.2 \%)$ \\
\hline $\mathrm{NHF}+/-\mathrm{IMV}$ & $5(29.4 \%)$ & $8(47.1 \%)$ & $13(38.2 \%)$ \\
\hline intubation & $17(100 \%)$ & $14(82.4 \%)$ & $31(91.2 \%)$ \\
\hline IMV days & $16 \pm 18(1-77)$ & $22 \pm 23(0-79)$ & $19 \pm 21(0-79)$ \\
\hline weaned respirator & $2(11.8 \%)$ & $12(70.6 \%)$ & $14(41.2 \%)$ \\
\hline \multicolumn{4}{|l|}{ day_1 (at controlled ventilation with highest PEEP level) } \\
\hline lowest $\mathrm{PaO} 2 / \mathrm{FiO}^{\mathrm{d}}$ & $109 \pm 42(60-227)$ & $129 \pm 19(82-148)$ & $114 \pm 33(60-227)$ \\
\hline $\mathrm{FiO} 2(\%)$ & $66 \pm 19(40-100)$ & $67 \pm 19(40-100)$ & $66 \pm 19(40-100)$ \\
\hline PEEP (mbar) & $13 \pm 3(7-18)$ & $12 \pm 3(7-17)$ & $13 \pm 3(7-18)$ \\
\hline P peak (mbar) & $29 \pm 5(17-37)$ & $27 \pm 5(19-36)$ & $28 \pm 5(17-37)$ \\
\hline compliance (ml/mbar) & $51 \pm 30(18-101)$ & $50 \pm 28(20-120)$ & $51 \pm 28(18-120)$ \\
\hline resistance $(\mathrm{mbar} / \mathrm{sec})$ & $12 \pm 3(7-17)$ & $12 \pm 4(3-17)$ & $12 \pm 4(3-17)$ \\
\hline tidal volume (ml) & $490 \pm 140(270-780)$ & $430 \pm 120(260-600)$ & $460 \pm 130(270-780)$ \\
\hline first spontaneous breathing ( $>10 \mathrm{~min}$.) in the first $24 \mathrm{~h}$ hours & $10(58.8 \%)$ & $15(88.2 \%)$ & $25(73.5 \%)$ \\
\hline \multicolumn{4}{|l|}{-} \\
\hline$\underline{\mathrm{ECMO}}$ & $5(29.4 \%)$ & $3(17.6 \%)$ & $8(23.5 \%)$ \\
\hline ECMO days & $22 \pm 30(2-75)$ & $16 \pm 7(8-20)$ & $20 \pm 23(2-75)$ \\
\hline weaned ECMO & $0 / 8$ & $3 / 8$ & $3(8.8 \%)$ \\
\hline \multicolumn{4}{|l|}{ therapeutic positioning } \\
\hline overall therapeutic positioning maneuvers ${ }^{b}$ & $16(94.1 \%)$ & $14(82.4 \%)$ & $30(88.2 \%)$ \\
\hline proning & $12(70.6 \%)$ & $11(64.7 \%)$ & $23(67.6 \%)$ \\
\hline rotational bed & $1(5.9 \%)$ & $1(5.9 \%)$ & $2(5.9 \%)$ \\
\hline $135^{\circ} /$ pilot & $3(17.6 \%)$ & $2(11.8 \%)$ & $5(14.7 \%)$ \\
\hline supine bedding & $1(5.9 \%)$ & $3(17.6 \%)$ & $4(11.8 \%)$ \\
\hline
\end{tabular}




\begin{tabular}{|c|c|c|c|}
\hline acute kidney injury ${ }^{\mathrm{C}}$ & $15(88.2 \%)$ & $14(82.4 \%)$ & $29(85.3 \%)$ \\
\hline renal replacement therapy & $6(35.3 \%)$ & $6(35.3 \%)$ & $12(35.3 \%)$ \\
\hline overall vasopressor therapy & $17(100 \%)$ & $11(64.7 \%)$ & $28(82.4 \%)$ \\
\hline no vasopressors & $0(0 \%)$ & $6(35.3 \%)$ & $6(17.6 \%)$ \\
\hline low vasopressors & $4(23.5 \%)$ & $8(47.1 \%)$ & $12(35.3 \%)$ \\
\hline mod. vasopressors & $4(23.5 \%)$ & $1(5.9 \%)$ & $5(14.7 \%)$ \\
\hline high vasopressors & $9(52.9 \%)$ & $2(11.8 \%)$ & $11(32.4 \%)$ \\
\hline packed red blood cells & $12(70.6 \%)$ & $5(29.4 \%)$ & $17(50 \%)$ \\
\hline
\end{tabular}

Abbreviations: ICU, intensive care unit; IMV, invasive mechanical ventilation; NIV, non-invasive ventilation; NIV +/- IMV or NHF, nasal high flow +/- IMV: Non-invasive strategy (NIV or NHF) followed by intubation or as exclusive strategy during ICU treatment; PEEP, positive end-expiratory pressure; P insp, inspiratory pressure; P peak, measured peak pressure; ECMO, extracorporeal membrane oxygenation.

${ }^{a}$ ICU resources are displayed for all patients, non-survivors and survivors. Data are $\mathrm{n}(\%)$ or mean with standard deviation and range.

${ }^{\mathrm{b}}$ Therapeutic positioning maneuvers included complete proning, incomplete proning $\left(135^{\circ}\right)$, pilot's seat positioning or the use of a rotational bed.

${ }^{\mathrm{c}}$ Acute kidney injury is defined by the RIFLE definition.

If values of non-survivors and survivors were significantly different $(\mathrm{p}<0.05)$, we displayed them bold: weaned respirator $\mathrm{p}<0.0001$; vasopressor therapy $\mathrm{p}=0.007$; transfusion $\mathrm{p}=0.016$;

Table 3: complications and outcomes 


\begin{tabular}{|c|c|c|c|}
\hline- & $\begin{array}{l}\text { non-survivor } \\
\qquad(n=17)\end{array}$ & $\begin{array}{l}\text { ICU-survivors } \\
\qquad(\mathrm{n}=17)\end{array}$ & $\begin{array}{l}\text { all patients } \\
\qquad(\mathrm{n}=34)\end{array}$ \\
\hline \multicolumn{4}{|l|}{$\underline{\text { complications }}^{\mathrm{a}}$} \\
\hline respiratory superinfection (initially) & $6(35.3 \%)$ & $5(29.4 \%)$ & $11(32.4 \%)$ \\
\hline respiratory superinfection (during treatment) & $9(52.9 \%)$ & $9(52.9 \%)$ & $18(52.9 \%)$ \\
\hline Serratia marcescens & $3(17.6 \%)$ & $3(17.6 \%)$ & $6(17.6 \%)$ \\
\hline Aspergillus fumigatus & $2(11.8 \%)$ & $0(0 \%)$ & $2(5.9 \%)$ \\
\hline other superinfection ${ }^{\mathrm{b}}$ & $4(23.5 \%)$ & $6(35.3 \%)$ & $10(29.4 \%)$ \\
\hline pneumothoraxes/pneumomediastinum & $4(23.5 \%)$ & $2(11.8 \%)$ & $6(17.6 \%)$ \\
\hline pulmonary embolism & $2(11.8 \%)$ & $3(17.6 \%)$ & $5(14.7 \%)$ \\
\hline Intracerebral hemorrhage & $5(29.4 \%)$ & $0(0 \%)$ & $5(14.7 \%)$ \\
\hline delirium & $1(5.9 \%)$ & $3(17.6 \%)$ & $4(11.8 \%)$ \\
\hline \multicolumn{4}{|l|}{$\underline{\text { cause of death }}^{\mathrm{C}}$} \\
\hline refractory respiratory failure & $3(17.6 \%)$ & & \\
\hline refractory multiorgan failure & $9(52.9 \%)$ & & \\
\hline fatal intracerebral hemorrhage & $3(17.6 \%)$ & & \\
\hline withdrawal due to DNR order & $2(11.8 \%)$ & & \\
\hline \multicolumn{4}{|l|}{ discharge place } \\
\hline weaning unit ${ }^{\mathrm{d}}$ & & $5(29.4 \%)$ & \\
\hline rehabilitation (without weaning) & & $2(17.6 \%)$ & \\
\hline home & & $10(58.8 \%)$ & \\
\hline survival since admission, days & & & $60 \pm 8(51-81)$ \\
\hline
\end{tabular}

${ }^{\text {a }}$ Complications are displayed for all patients, non-survivors and survivors. Data are $\mathrm{n}(\%)$.

b Other superinfections included Haemophilus influenza, Streptokokkus pneumonia, Staphylococcus aureus, Pseudomonas aeruginosa.

If values of non-survivors and survivors were significantly different $(p<0.05)$, we displayed them bold: intracerebral hemorrhage $p=0.015$

${ }^{\mathrm{c}}$ Cause of death was analyzed for the 17 deceased patients according to clinical judgement. No medical autopsies were carried out. Data are $\mathrm{n}$ (\%).

DNR order $=$ do not resuscitate order

d Transferals to weaning units included 4 transferals to an incorporated weaning unit and 1 transferal to an external weaning unit. 


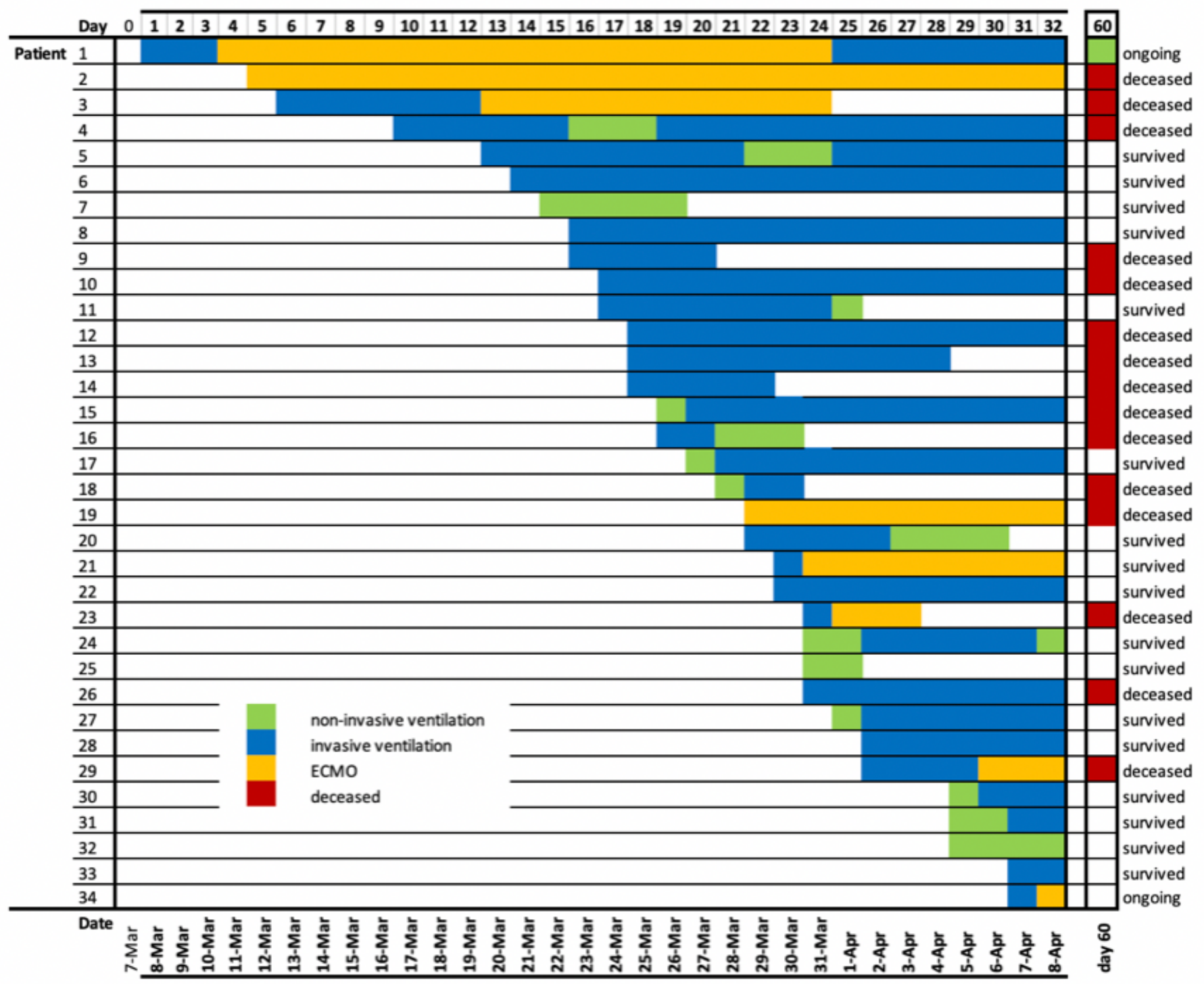

Figure 1

Clinical courses and outcomes of critically ill COVID-19 patients. Date of admission, clinical course and outcomes are depicted for each patient until 05/28/2020. Days with non-invasive ventilation (noninvasive oxygen support; green), invasive ventilation (blue) and additional extracorporeal membrane oxygenation (ECMO; orange) are displayed. 

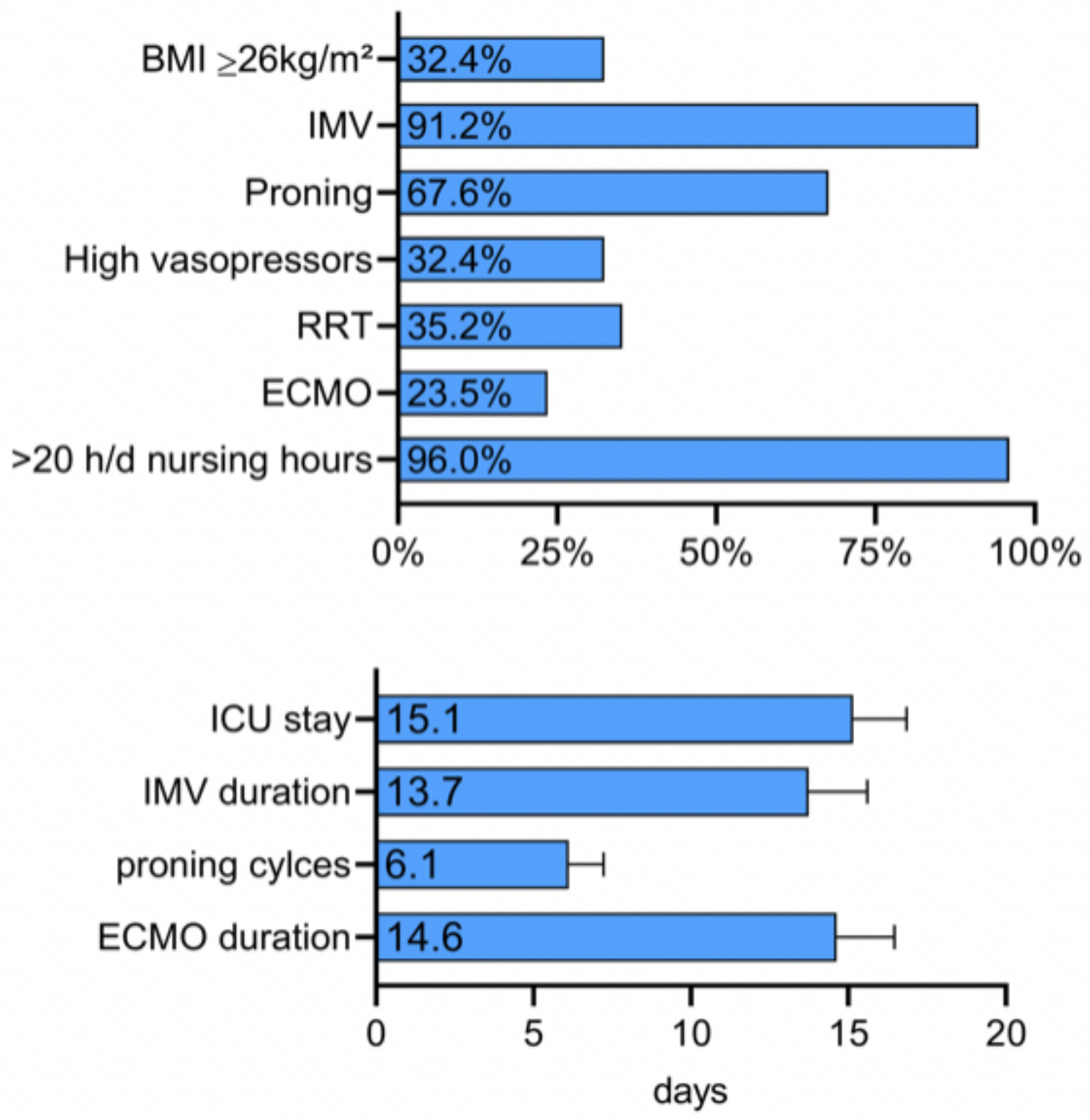

Figure 2

Intensive care resources and therapies in critically ill COVID-19 patients. Cumulative intensive care resources and therapies are displayed in \%. The average of length of stay, invasive mechanical ventilation (IMV) days, proning cycles and days of extracorporeal membrane oxygenation (ECMO) therapy are displayed in days or cycles.

\section{Supplementary Files}

This is a list of supplementary files associated with this preprint. Click to download.

- 4SupplementalmateriaICOVID19ICU.docx 